\title{
Development of solar home system with dual energy storage
}

\author{
Bin-Juine Huang ${ }^{1}$ ( $)$ Po-Chien Hsu ${ }^{1} \cdot$ Yi-Hung Wang ${ }^{1} \cdot$ Tzu-Chiao Tang $^{1} \cdot$ Jia-Wei Wang ${ }^{1} \cdot$ Xin-Hong Dong $^{1}$. \\ Ming-Jia Lee ${ }^{1} \cdot$ Jen-Fu Yeh ${ }^{1} \cdot$ Zi-Ming Dong ${ }^{1} \cdot$ Min-Han $\mathrm{Wu}^{1} \cdot$ Shen-Jie Sia ${ }^{1} \cdot \mathrm{Kang} \mathrm{Li}^{1} \cdot \mathrm{Kung}^{-Y e n} \mathrm{Lee}^{2}$
}

(c) Springer Nature Switzerland AG 2019

\begin{abstract}
Distributed energy generation with energy storage is quite important for high penetration of solar PV energy. A solar home system which generates solar power for self-consumption was studied. The solar home system utilizes a switchingtype solar PV (HyPV) which operates in either solar or grid mode automatically without feeding solar power into grid. The solar home system also uses dual energy storage consisting of a battery and an electric water heater which stores PV energy as hot water (thermal storage) when the battery is full. Since thermal storage is much cheaper than battery, the dual energy storage would reduce the total cost of solar home system dramatically. Four HyPV solar home systems were built to run long-term field test. The results show that the specific PV energy generation approximates that of feedin-tariff PV system. A solar PV energy production cost analysis shows that the HyPV solar home system with dual storage is economic if it was used to replace partial energy demand which is paid at higher grid electricity price. This verifies the possibility of grid parity for a solar PV system with energy storage.
\end{abstract}

Keywords Solar PV system · Solar home system · Solar PV with storage

\section{Introduction}

High penetration of solar photovoltaic (PV) energy using grid-tied PV system may cause grid transmission problems. Distributed energy generation with energy storage is a good choice to cope with this problem. However, the cost of energy storage is very high and the solar PV system may not be economic.

Hsu et al. [1, 2] developed a hybrid solar PV system (HyPV) as shown in Fig. 1. HyPV operates in stand-alone PV mode or grid mode automatically using switching technique. No solar power is fed into grid. When solar energy is available, including PV power generation and battery storage, it operates in PV mode and the load is powered completely by solar energy as a stand-alone PV. When PV power generation and battery storage is low, it switches to grid mode through ATS (Automatic Transfer Switch). The load is supplied completely by grid, and the battery is charged again by solar PV. HyPV will switch back to PV mode when the battery is charged certain amount of energy.

Solar home system generating electrical power using HyPV with storage device for self-consumption was further proposed [3]. This kind of PV system is usually in small size (1-3 kWp) and looks like a home appliance. Thus, it can be combined with hot water supply system since there is always a hot water demand in a household. Since the thermal storage is much cheaper than battery, this will reduce the cost of energy storage dramatically.

Since no solar PV power is fed into the grid in HyPV, the energy storage has to be large enough in order to avoid the PV energy generation loss. An electric water heater is used to store PV energy as heat to provide enough storage capacity, called "HyPV solar home system" (Fig. 2). In PV mode, the PV energy will be stored as hot water (thermal storage) by the electric heater through ATS2 when the

$\triangle$ Bin-Juine Huang, bjhuang@seed.net.tw | ${ }^{1}$ Department of Mechanical Engineering, National Taiwan University, Taipei 106, Taiwan. ${ }^{2}$ Department of Engineering Science and Ocean Engineering, National Taiwan University, Taipei 106, Taiwan.

SN Applied Sciences (2019) 1:973 | https://doi.org/10.1007/s42452-019-1000-8 


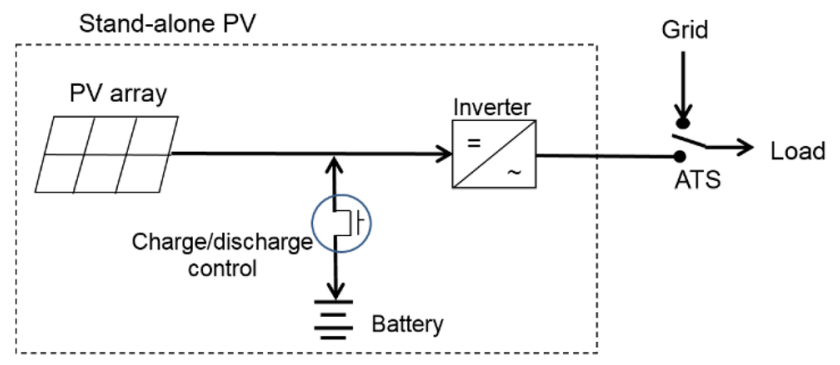

Fig. 1 Schematic diagram of HyPV [1]

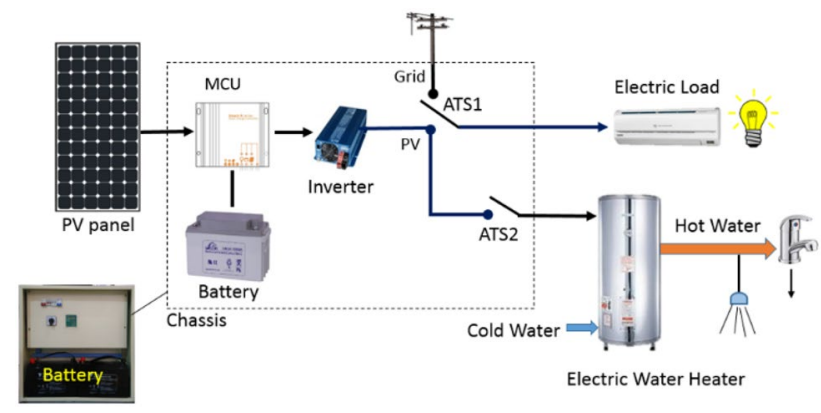

Fig. 2 HyPV solar home system with dual energy storage

battery is full. Since thermal storage is much cheaper than battery, the dual energy storage would reduce the total cost of HyPV solar home system.

Bocklisch [4] discussed hybrid energy storage (HESS) for power flow control for peak shaving. Lee [5] theoretically studied solar lighting system with battery and heater which stores PV energy at daytime when the battery is full.

Akbaria et al. [6] reviewed all types of energy storage systems that can be integrated with PV system consisting of electrical and thermal energy storage. The integration of PV energy storage in smart buildings is discussed together with the role of energy storage for PV in the context of future energy storage developments. The future energy storage development was summarized, and even demandside energy management was discussed. It is shown that thermal storage will satisfy thermal comfort needs of buildings when operating with heat pumps while battery deployment may operate with electric vehicles and/or electric heat pumps at times of local grid congestion.

Faccia et al. [7] analyzed the transition from natural gas to electricity-based heating for residential applications, considering the interplay between grid-tied solar PV electricity generation on site and the thermal energy storage to optimize the heating devices. The analysis found that if heat pumps are used instead of natural gas boilers, energy costs are reduced up to $41 \%$. The simultaneous utilization of heat pumps (as substitutes of boilers) and PV panels is shown to be economic and yields grid parity.
The studies of [3-9] are all related to grid-tied solar PV system with energy storage, and no experimental data were reported. The present HyPV solar home system is basically a stand-alone PV combined with grid power through a switching device. No PV power is fed into grid to cause possible grid congestion. Hence, the solar system requires a larger energy storage to obtain high PV generation efficiency. This may lead to high cost.

The present study focuses on the technical feasibility of non-grid-tied solar home system with dual energy storage. Four HyPV solar home systems with dual energy storage were built for field test to collect the long-term performance data. Solar energy production cost was also analyzed.

\section{Installation of HyPV system}

\subsection{Design of HyPV systems}

Four HyPV systems were built in the present study. The system design specification is shown in Table 1. Three of them (D3, D5, and D11) were installed in household to collect data in real application as a home appliance. The PV power is used to drive 2 or 3 air conditioners and LED lighting in the house. The city water is preheated by solar PV power when the battery is full. The $120 \mathrm{~L}$ water heater with electric heating element provides $4.2 \mathrm{kWh}$ thermal storage capacity $\left(E_{w}\right)$ for water temperature rise $\Delta T=30^{\circ} \mathrm{C}$ which is larger than the usable battery capacity $\left(E_{b a t}\right)$.

As shown in Table 1, the ratio of battery storage to maximum PV energy generation $\left(E_{b a t} / E_{p v}\right)$ for the four HyPVs is all less than 1.0. This will cause solar PV energy generation loss if only battery storage is used. In the present study, the total usual energy storage capacity $\left(E_{\text {tot }}\right)$ including battery and hot water storage ranges from 5.35 to $7.08 \mathrm{kWh}$. With this combination, the ratio of total energy storage to expected solar PV energy generation $\left(E_{t o t} / E_{p v}\right)$ ranges from 1.36 to 2.11 . It is known that the FIT solar PV systems generate maximum solar power which is directly fed into grid at optimal energy conversion efficiency since the MPPT (maximum power point tracking) was always used. This means that the designed total energy storage capacity $\left(E_{t o t}\right)$ including battery and hot water storage is large enough to store the daily solar PV energy generation, if the daily hot water load is larger than $4.2 \mathrm{kWh}$.

\subsection{Installation of HyPV systems}

Figures 3, 4, 5 and 6 show the installation of four HyPVs in Taipei and Chia-Yi (southern Taiwan). D3 was installed in a resident house surrounded by apartment buildings. D5 was installed at the top of an 7-floor apartment building. 
Table 1 System design specification of four HyPVs

\begin{tabular}{|c|c|c|c|c|}
\hline HyPV & D3 & D5 & D8 & D11 \\
\hline Installation location & Taipei & Taipei & Taipei & Chia-Yi \\
\hline Specific energy generation of FIT PV system $\left(S_{p v}\right)(\mathrm{kWh} / \mathrm{kWp}$ per day) & 2.47 & 2.47 & 2.47 & 3.84 \\
\hline \multicolumn{5}{|l|}{ PV Module } \\
\hline Size $\left(P_{p v}\right)(\mathrm{kWp})$ & 1.47 & 1.47 & 1.08 & 1.08 \\
\hline Expected PV energy generation $\left(E_{p v}\right)(\mathrm{kWh} /$ day) & 3.63 & 3.63 & 2.67 & 4.15 \\
\hline \multicolumn{5}{|l|}{ Battery } \\
\hline Type & LA & $\mathrm{Li}$ & LA & LA \\
\hline Voltage (V) & 48 & 48 & 24 & 24 \\
\hline $\operatorname{Capacity}\left(E_{\text {bato }}\right)(\mathrm{kWh})$ & 4.8 & 1.44 & 2.4 & 2.4 \\
\hline Usable capacity $\left(E_{b a t}\right)[\mathrm{kWh} @ \mathrm{DOD} 60 \%(\mathrm{LA})$ or $80 \%(\mathrm{Li})]$ & 2.88 & 1.15 & 1.44 & 1.44 \\
\hline Cost of battery (TWD) & 19,200 & 28,800 & 9600 & 9600 \\
\hline \multicolumn{5}{|l|}{ Water heater } \\
\hline Tank volume (L) & 120 & 120 & 120 & 120 \\
\hline Power input $(\mathrm{kW})$ & 1.0 & 1.0 & 0.7 & 0.7 \\
\hline Heat storage capacity $\left(E_{w}\right)\left(\mathrm{kWh} @ \Delta \mathrm{T}=30^{\circ} \mathrm{C}\right)$ & 4.2 & 4.2 & 4.2 & 4.2 \\
\hline Cost of water heater (TWD) & 8400 & 8400 & 8400 & 8400 \\
\hline Total usable energy storage capacity $\left(E_{\text {tot }}=E_{b a t}+E_{w}\right)(\mathrm{kWh})$ & 7.08 & 5.35 & 5.64 & 5.64 \\
\hline Inverter (kW @220 V) & 1.5 & 1.5 & 1.5 & 1.5 \\
\hline \multicolumn{5}{|l|}{ Load } \\
\hline Type & Cooling, lighting & Cooling, lighting & Cooling & Cooling \\
\hline Load power (kW) & $0.2-1.4$ & $0.2-1.2$ & $0.2-1.2$ & $0.2-1.2$ \\
\hline Load pattern & $24 \mathrm{~h}$ a day & Night & $24 \mathrm{~h}$ a day & Night \\
\hline Ratio of usable battery storage to max PV energy generation $E_{b a t} / E_{p v}$ & 0.79 & 0.32 & 0.54 & 0.35 \\
\hline Ratio of total usable energy storage to $\max (\mathrm{FIT}) \mathrm{PV}$ energy generation $E_{t o t} / E_{p v}$ & 1.95 & 1.47 & 2.11 & 1.36 \\
\hline Total cost of dual energy storage (TWD) & 27,600 & 37,100 & 18,000 & 18,400 \\
\hline Total cost of energy storage using Li battery only (TWD) & 177,000 & 133,750 & 141,000 & 141,000 \\
\hline
\end{tabular}

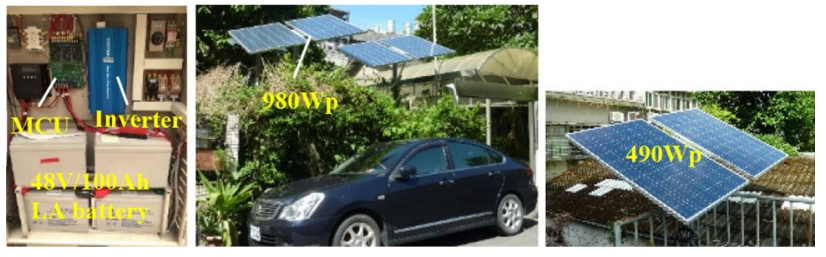

Fig. 3 HyPV D3 installed in a house (Taipei)

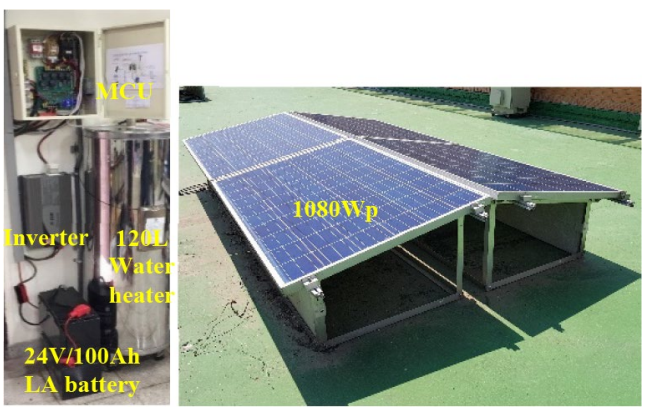

Fig. 5 HyPV D8 installed in laboratory (Taipei)
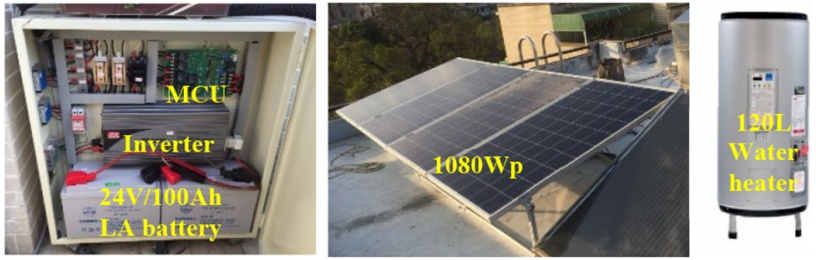

Fig. 6 HyPV D11 installed in a house (Chia-Yi)

Fig. 4 HyPV D5 installed in an apartment (Taipei) 


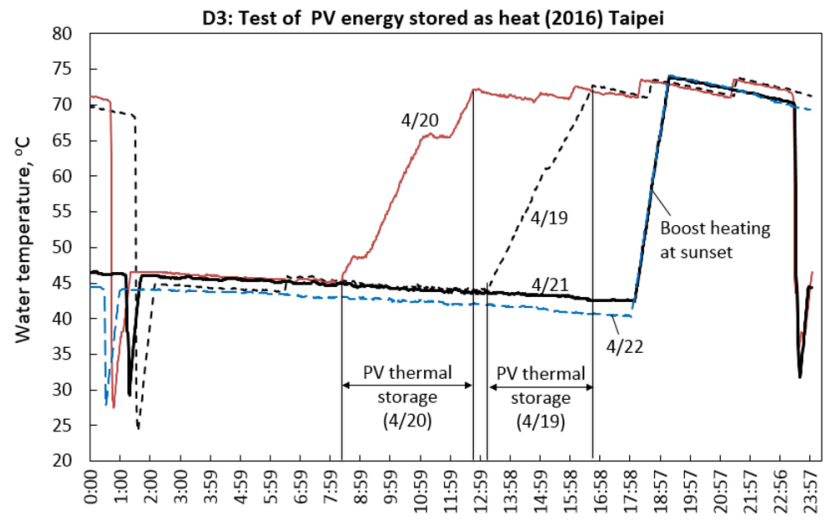

Fig. 7 Performance of solar PV thermal storage in D3

D8 was installed at the solar energy laboratory, National Taiwan University, on the rooftop of a building. D11 was installed in Chia-Yi, southern part of Taiwan, in a residential house. Only D5 utilizes Li battery in the dual energy storage. D3, D8, and D11 utilize lead-acid (LA) battery.

The microprocessor-based power control unit (MCU) monitors the instantaneous performance of HyPV. All the data are remotely transmitted to a PC in the laboratory at National Taiwan University, except D5 without internet.

\section{Field test results}

The four HyPV systems are run continuously on side.

\subsection{HyPV-D3}

Figure 7 shows the performance of thermal storage in $\mathrm{D} 3$. On 2016/4/19 and 2016/4/20, the PV power drives the water heater to store PV energy as heat since there is no electric load in daytime. The hot water heater stores PV energy from 42 to $72{ }^{\circ} \mathrm{C}$, about $4.2 \mathrm{kWh}$. The water heater is boosted to $70{ }^{\circ} \mathrm{C}$ (set temperature) at sunset if the PV energy is insufficient for hot water supply at night.

Figure 8 shows the long-term performance of D3 with PV energy storage as heat. The hot water temperature reaches $70^{\circ} \mathrm{C}$ in winter, spring, and fall when the air conditioners are not used. Figure 9 shows the daily energy supply from solar PV and grid. It shows that the solar PV supplies $24 \%$ of the total load. The long-term average specific PV energy generation of D3 in 2016 (Fig. 10) is $1.84 \mathrm{kWh} /$ kWp per day (Fig. 9) which is about $20 \%$ lower than that of FIT solar PV system (2.47) in Taipei. This is due to the shadow effect caused by surrounding buildings which is quite serious in afternoon between October and March.

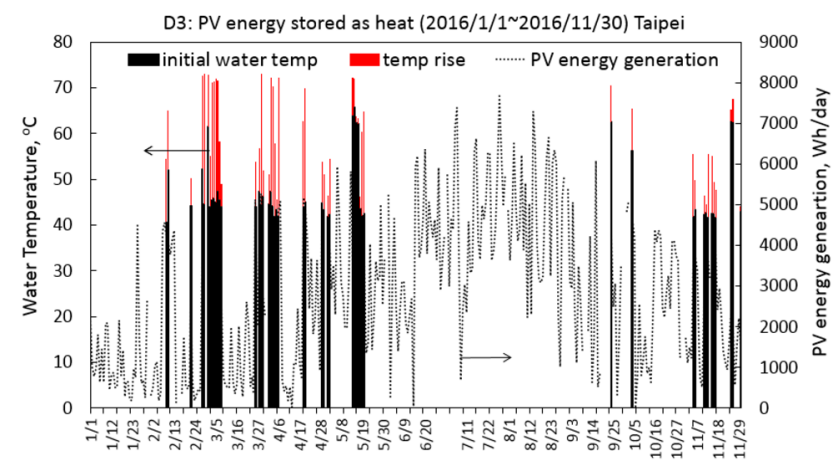

Fig. 8 Performance of D3 with PV thermal storage

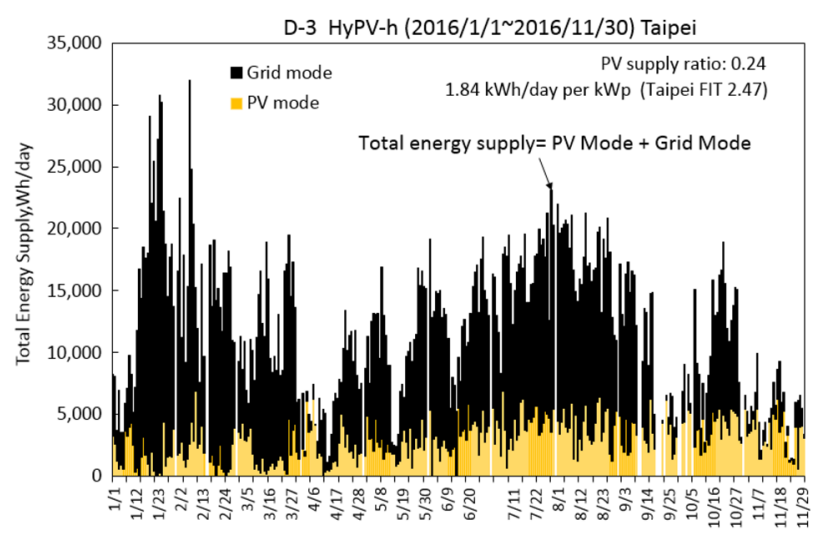

Fig. 9 Energy supply of D3

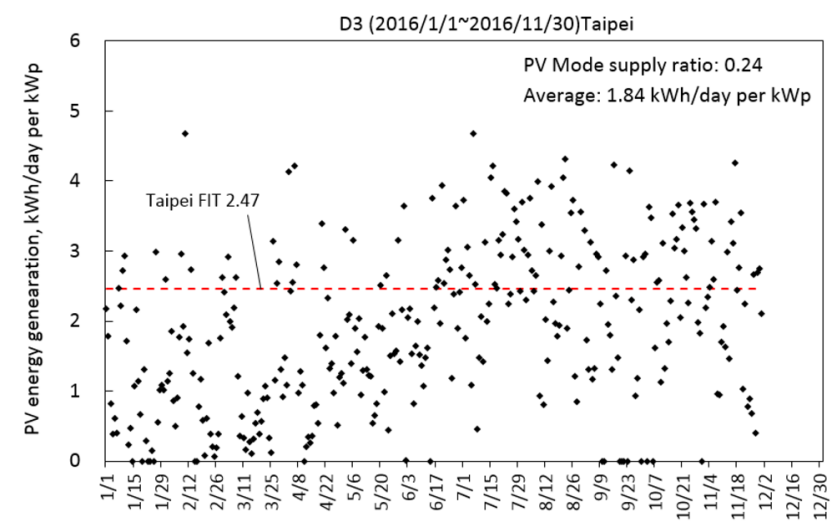

Fig. 10 Daily specific PV energy generation of D3 in 2016

\subsection{HyPV-D5}

D5 was installed on the rooftop of an apartment building. No remote monitoring system was installed. The performance was monitored through regular metering. Table 2 shows the average performance of D5 in about a year. The average specific PV energy generation of D5 in 2016 
Table 2 Average performance of D5 (2015/5/21-2016/5/31)

$\begin{array}{ll}\text { PV generation (kWh/day) } & 3.80\end{array}$

Energy consumption of air conditioners (kWh/day) $\quad 5.40$

Energy consumption of water heater (kWh/day) $\quad 1.00$

Total load (kWh/day) $\quad 6.40$

Specific PV energy generation ( $\mathrm{kWh} / \mathrm{kWp}$ per day) (grid-tied $\quad 2.59$ FIT PV in Taipei: 2.47)

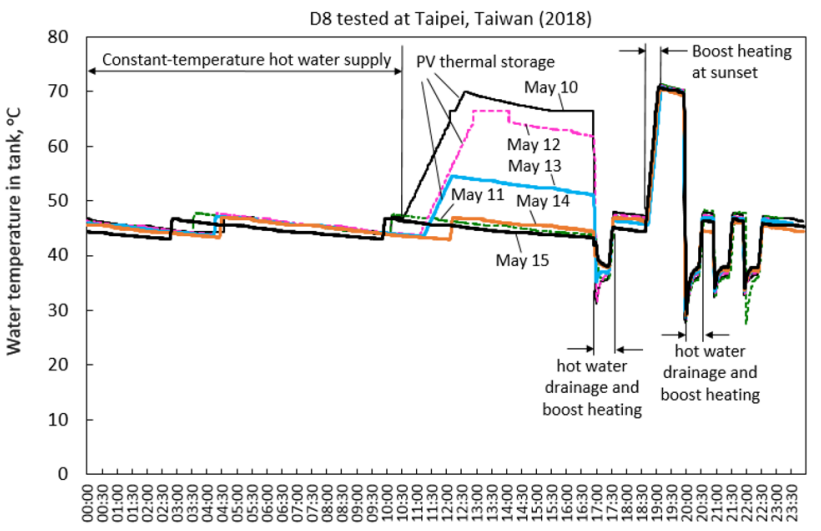

Fig. 11 PV thermal storage of D8

is $2.59 \mathrm{kWh} / \mathrm{kWp}$ per day which is about $5 \%$ higher than that of FIT solar PV system (2.47) in Taipei.

\subsection{HyPV-D8}

D8 was installed in the laboratory with regular hot water drainage control to simulate real application in home. Figure 11 shows the water temperature variation during PV thermal storage. It is seen that solar PV energy was stored as heat when the battery is fully charged and the load is not in use. D8 also performed boost heating at sunset if the water temperature is below $70^{\circ} \mathrm{C}$. Table 3 is the daily performance of D8 in May 2018. Figure 12 shows the average specific PV energy generation of D8 in May 2018 is $4.05 \mathrm{kWh} / \mathrm{kWp}$ per day which is about $64 \%$ higher than that of FIT solar PV system (2.47) in Taipei. This is due to the good weather in May which is better than the whole year average.

\subsection{HyPV-D11}

D11 was installed in early 2018 in a resident house in Chia$\mathrm{Yi}$ (southern part of Taiwan). It is clearly seen from battery voltage variation that PV power was converted into heat storage when the battery is fully charged as shown in Figs. 13 and 14. Table 4 shows that the average specific PV energy generation of $D 11$ is $4.35 \mathrm{kWh} / \mathrm{kWp}$ per day which is about $13 \%$ higher than that of FIT solar PV system (3.84) in Chia-Yi. This is because the data collected are not long enough to cover the whole year.

\subsection{Overall performance comparison}

The performance of four HyPVs (D3, D5, D8, and D11) can be compared. It is seen from Table 5 that the average specific PV energy generation is all near that of FIT solar PV system installed locally, except D3 which has serious shadow effect between October and March. This verifies that the dual energy storage in HyPV can eliminate solar $\mathrm{PV}$ generation loss due to system mismatch. By using thermal storage, the cost of energy storage can be reduced.

Table 3 Daily performance of D8 in 2018

\begin{tabular}{|c|c|c|c|c|c|c|c|}
\hline Date & $\begin{array}{l}\text { Solar irradiation } \\
\left(\mathrm{Wh} / \mathrm{m}^{2}\right)\end{array}$ & $\begin{array}{l}\text { PV genera- } \\
\text { tion (Wh) }\end{array}$ & $\begin{array}{l}\text { Energy supplied } \\
\text { by PV (Wh) }\end{array}$ & $\begin{array}{l}\text { Thermal stor- } \\
\text { age }(\mathrm{Wh})\end{array}$ & $\begin{array}{l}\text { Total PV energy } \\
\text { supply (Wh) }\end{array}$ & $\begin{array}{l}\text { Specific PV generation } \\
\text { (kWh/kWp per day) }\end{array}$ & $\begin{array}{l}\text { PV system } \\
\text { efficiency }\end{array}$ \\
\hline $5 / 12$ & 6423 & 4690 & 2328 & 1588 & 3916 & 4.69 & 0.114 \\
\hline $5 / 13$ & 4543 & 3460 & 2801 & 783 & 3584 & 3.46 & 0.119 \\
\hline $5 / 14$ & 5068 & 3740 & 3428 & 0 & 3428 & 3.74 & 0.115 \\
\hline $5 / 15$ & 3470 & 2530 & 2542 & 0 & 2542 & 2.53 & 0.114 \\
\hline $5 / 17$ & 5142 & 4220 & 3542 & 0 & 3542 & 4.22 & 0.128 \\
\hline $5 / 18$ & 6210 & 4870 & 4672 & 0 & 4672 & 4.87 & 0.123 \\
\hline $5 / 20$ & 5787 & 4910 & 4851 & 0 & 4851 & 4.91 & 0.133 \\
\hline $5 / 21$ & 4396 & 3750 & 3476 & 0 & 3476 & 3.75 & 0.133 \\
\hline $5 / 23$ & 3518 & 2920 & 2778 & 0 & 2778 & 2.92 & 0.130 \\
\hline $5 / 24$ & 5749 & 4660 & 4490 & 0 & 4490 & 4.66 & 0.127 \\
\hline $5 / 25$ & 4688 & 3840 & 3757 & 0 & 3757 & 3.84 & 0.128 \\
\hline $5 / 26$ & 5741 & 4750 & 4610 & 0 & 4610 & 4.75 & 0.129 \\
\hline $5 / 27$ & 6336 & 4970 & 4819 & 0 & 4819 & 4.97 & 0.123 \\
\hline $5 / 28$ & 4472 & 3690 & 3565 & 0 & 3565 & 3.69 & 0.129 \\
\hline $5 / 29$ & 4557 & 3780 & 3654 & 0 & 3654 & 3.78 & 0.130 \\
\hline Average & 5073 & 4052 & 3688 & 0 & 3846 & 4.05 & 0.125 \\
\hline
\end{tabular}




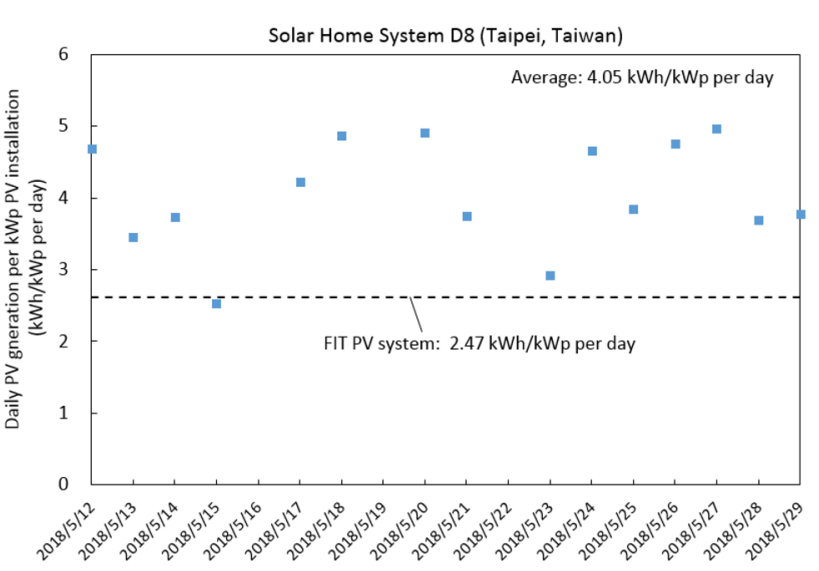

Fig. 12 Daily specific PV energy generation of D8 in May

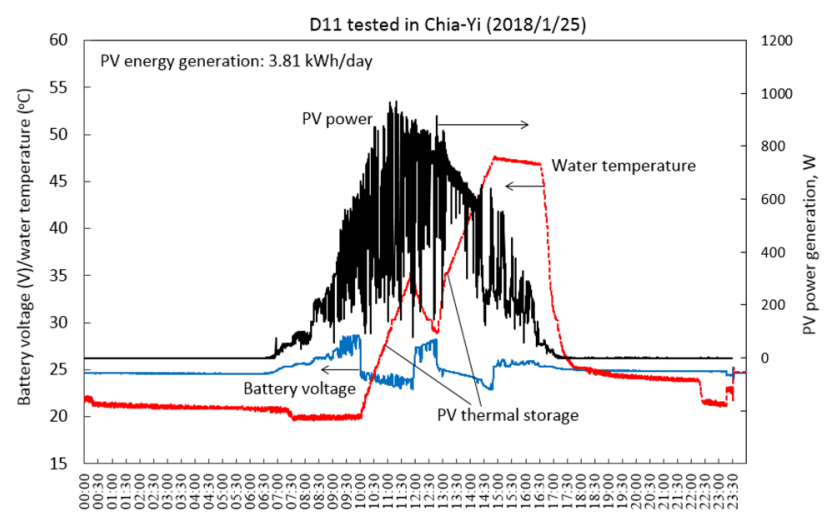

Fig. 13 Performance of solar PV thermal storage (1/25)

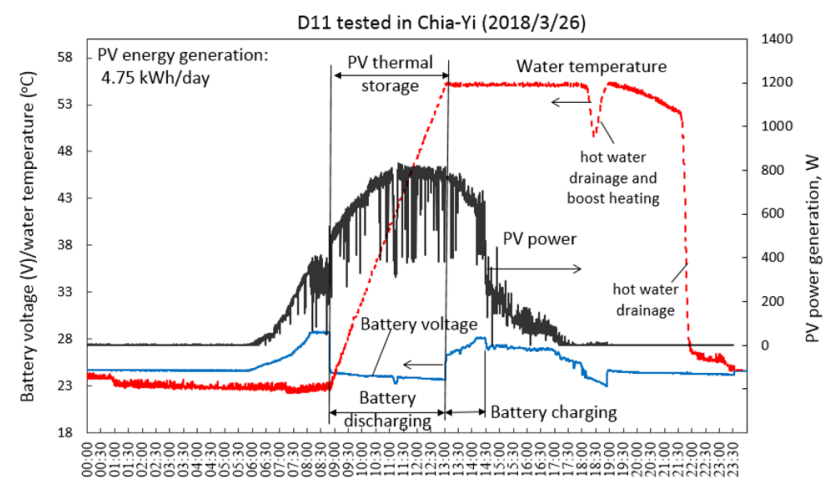

Fig. 14 Performance of solar PV thermal storage (3/26)

\section{PV production cost analysis}

To analyze the PV production cost, a long-term system analysis is carried out using the performance model of HyPV and meteorological data with different system design parameters and load pattern.
Table 4 Test results of D11

\begin{tabular}{lll}
\hline Date & $\begin{array}{l}\text { PV generation (kWh/ } \\
\text { day) }\end{array}$ & $\begin{array}{l}\text { Specific PV genera- } \\
\text { tion (kWh/kWp per } \\
\text { day) }\end{array}$ \\
\hline $2018 / 1 / 25$ & 3.81 & 3.53 \\
$2018 / 2 / 25$ & 4.20 & 3.89 \\
$2018 / 3 / 22$ & 5.68 & 5.26 \\
$2018 / 3 / 24$ & 5.45 & 5.05 \\
$2018 / 3 / 26$ & 4.75 & 4.40 \\
$2018 / 3 / 31$ & 4.27 & 3.95 \\
Average & 4.69 & 4.35 \\
\hline
\end{tabular}

3.84 kWh/kWp per day for FIT grid-tied PV systems in the same location

\subsection{System simulation model}

In the HyPV, the incident solar radiation $\left(I_{T}\right)$ is absorbed and converted into electricity $P_{p v}$ which drives the load $\left(P_{L}\right)$ and charges the battery $\left(P_{b a t}\right)$, as shown in Fig. 15 . The energy balance equation, Eq. (1), is derived [1].

$P_{\text {bat }}=P_{\mathrm{pv}}-P_{\mathrm{L}}$

The battery charging will be cut off and the PV power generation approximates the load power, if it is fully charged. This will results in a PV generation loss. That is, there are two operating states in PV power generation as described in Eq. (2).

$\frac{\mathrm{d} E_{\mathrm{b}}(t)}{\mathrm{d} t} \approx \begin{cases}P_{\mathrm{pv}}-P_{\mathrm{L}}, & \text { battery not fully charged } \\ 0, & \text { battery fully charged }\end{cases}$

where $E_{b}$ is the battery storage level (i.e., state of charge-SOC).

\subsection{System analysis}

The long-term system simulation for different design parameters was carried out using the local meteorological data. Four load patterns are used in the present study: load pattern $A$ (100\% energy used in daytime 6:00-18:00), load pattern B (75\%), load pattern C (50\%), and load pattern D (25\%). Total PV energy generation over 20 years was calculated. The total investment cost includes initial and maintenance costs. Table 6 is the cost structure of HyPV solar home system used in the economic analysis.

Three parameters are defined, Eq. (3), to correlate the long-term system performance results:

$R_{p L}=\frac{P_{p v}}{P_{L}} ; \quad R_{h b}=\frac{E_{h}}{E_{b a t}} ; \quad t_{b p}=\frac{E_{b a t}}{P_{p v}}$

$R_{p L}$ is defined as the ratio of maximum PV power generation $\left(P_{p v}\right)$ to load power $\left(P_{L}\right) ; R_{h b}$ is the ratio of thermal 
Table 5 Overall performance comparison of D3, D5, D8, and D11

\begin{tabular}{lllll}
\hline HyPV & D3 & D5 & D8 & D11 \\
\hline Test period & $2016 / 1 / 1-$ & $2015 / 5 / 21-$ & $2018 / 5 / 12-$ & $2018 / 1 / 25-$ \\
& $2016 / 11 / 30$ & $2016 / 5 / 31$ & $2018 / 5 / 29$ & $2018 / 3 / 31$ \\
$\begin{array}{c}\text { Specific PV generation } \\
\text { (kWh/kWp per day) }\end{array}$ & 1.84 & 2.59 & 4.05 & 4.35 \\
FIT PV system & 2.47 & 2.47 & 2.47 & 3.84 \\
\hline
\end{tabular}

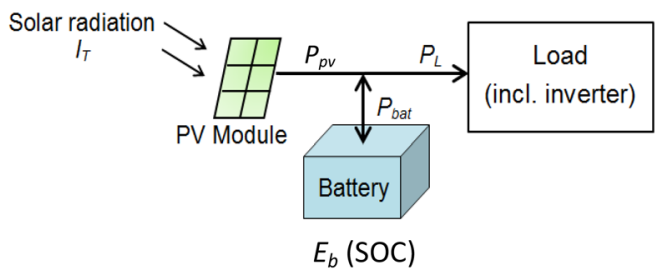

Fig. 15 Energy balance of HyPV in PV mode

Table 6 Cost of HyPV components used in economic analysis

\begin{tabular}{ll}
\hline Item & Unit price (1 USD=31 TWD) \\
\hline Solar PV system & 24 TWD/Wp \\
Li battery storage & 20 TWD/Wh \\
Thermal storage & 2 TWD/Wh \\
Inverter & 10 TWD/W \\
System Installation & $15 \mathrm{TWD} / \mathrm{Wp}$ \\
BOS & $10 \mathrm{TWD} / \mathrm{Wp}$ \\
Tax and gross profit & $25 \%$ \\
Maintenance & $2 \%$ initial cost per year \\
Cycle life of Li battery & 4000 cycles @80\%DOD \\
\hline
\end{tabular}

storage $\left(E_{h}\right)$ to battery storage $\left(E_{b a t}\right)$; and $t_{b p}$ is the charge time for solar PV to fully charge the battery.

\subsection{PV energy production cost}

Figure 16 is the variation of PV energy generation cost with $R_{p L}$. It shows that there is an optimal design for PV generation cost. The optimal ratio of maximum $\mathrm{PV}$ generation $P_{p v}$ to load power $P_{L}\left(R_{p L}\right)$ is between 1.7 and 2.2.

Figure 17 is the variation of PV generation cost with $R_{h b}$. An optimal design for PV generation cost can be found. The optimal ratio of thermal to battery storage capacity $\left(R_{h b}\right)$ is between 1 and 6 , depending on $t_{b p}$ (ratio of battery size to PV module installed). It is seen from Figs. 16 and 17 that the PV energy production cost decreases with decreasing $t_{b p}$. That is, smaller battery is more economic.

The grid electricity price in Taiwan is categorized in staircase structure (higher electricity consumption

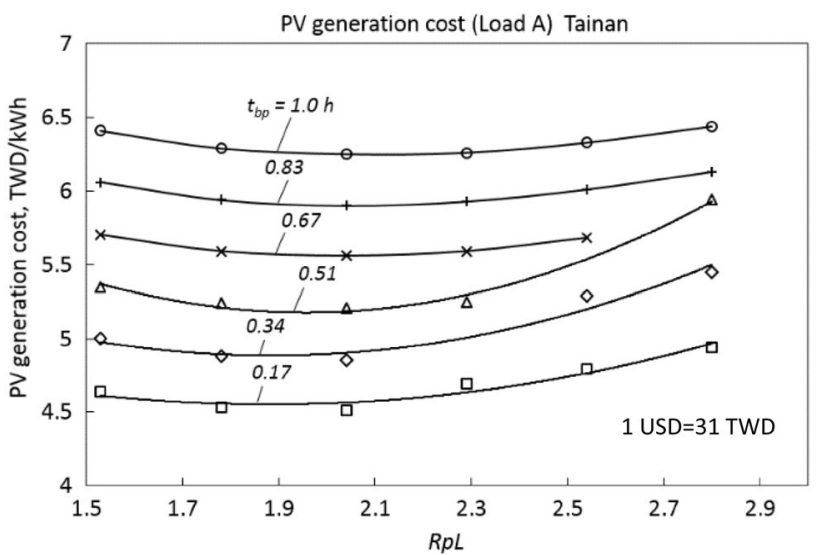

Fig. 16 Variation of PV generation cost with $R_{p L}$

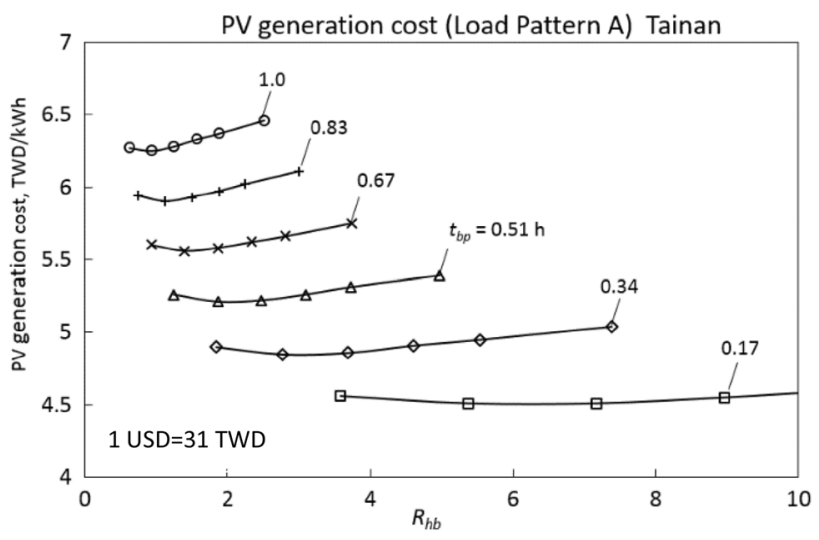

Fig. 17 Variation of PV generation cost with $R_{h b}$

paying higher unit price). The grid electricity price forecast for the next 20 years is shown in Fig. 18, according to the government policy. The PV generation cost from system simulation for 20 years at different designs is then compared with the average grid electricity price. Table 7 shows the optimal design for four kinds of load patterns in three cities of Taiwan. It is seen that the PV energy production cost is among 4.66-7.24 TWD/kWh (1 $\mathrm{USD}=31 \mathrm{TWD}$ ). For load pattern $\mathrm{A}-\mathrm{C}$, the present HyPV 


\begin{tabular}{ccc|cccc|}
\multicolumn{1}{c|}{$\begin{array}{c}\text { Present price, } \\
\text { TWD/kWh }\end{array}$} & $\begin{array}{c}\text { Monthly } \\
\text { consumption, } \\
\text { kWh/mon }\end{array}$ & $\begin{array}{c}\text { Yearly price } \\
\text { increase, } \\
\text { \%/y }\end{array}$ & $\begin{array}{c}\text { Price after } \\
\text { 20 years, } \\
\text { TWD/kWh }\end{array}$ & $\begin{array}{c}\text { Average } \\
\text { price, } \\
\text { TWD/kWh }\end{array}$ \\
\cline { 2 - 7 } & Category 6 & 6.12 & $>1000$ & 4.6 & 15.04 & 10.58 \\
\cline { 2 - 7 } & Category 5 & 5.42 & $701-1000$ & 4 & 11.88 & 8.65 \\
\hline Category 4 & 4.64 & $501-700$ & 3.4 & 9.06 & 6.85 \\
\hline Category 3 & 3.52 & $331-500$ & 2.8 & 6.12 & 4.82 \\
\hline Category 2 & 2.38 & $121-330$ & 2.2 & 3.68 & 3.03 \\
\hline Category 1 & 1.63 & $<121$ & 1.6 & 2.24 & 1.93 \\
\hline
\end{tabular}

Fig. 18 Grid electricity price in Taiwan (1 USD = 31 TWD)

solar home system with dual energy storage is economic if it was used to substitute partial energy demand (29-59\%) which is paid at higher grid electricity price (Category 3 or 4 ). For load pattern D (worst case), the solar home system is economic if it is used to substitute $17-20 \%$ of daily energy demand which is paid at higher grid electricity price (Category 4 or 5). This is the partial grid parity.

\subsection{Cost reduction of dual energy storage}

The above economic analysis is for HyPV solar home systems with Li battery and hot water storage. For the four HyPV solar home systems built and tested as described in Sects. 2 and 3, only D5 utilizes Li battery. We can compare the total energy storage cost at various combinations. Using the same design of HyPV D3, D5, D8, and D11, we can calculate the total energy storage cost at various combinations as shown in Table 8.

It is seen that the dual energy storage would reduce the energy storage cost by $72-87 \%$ if using Li battery only and $41-52 \%$ if using LA battery only except D5. D5 utilizes a rather large heat storage (about $78 \%$ of total energy storage capacity), and this causes no cost reduction even using all LA battery to replace it. That is, using LA battery only to replace Li battery and the cheaper and larger thermal storage (4.2 kWh) in D5 will increase the total energy storage cost because the heat storage used is relatively large. This can explain the existence of optimal $R_{p L}$ (ratio of maximum PV generation $P_{p v}$ to load power $P_{L}$ ) and $R_{h b}$ (ratio of thermal storage $E_{h}$ to battery storage $\left.E_{b a t}\right)$ in Figs. 16 and 17 .

Table 7 Optimal design and economic feasibility

\begin{tabular}{|c|c|c|c|c|c|c|c|c|c|c|c|c|}
\hline & $R_{h b}$ & $R_{p L}$ & $t_{b p}(\mathrm{~h})$ & $\begin{array}{l}\text { Battery } \\
\text { capacity } \\
\text { (Wh) }\end{array}$ & $\begin{array}{l}\text { Solar PV } \\
\text { panel } \\
(\mathrm{Wp})\end{array}$ & $\begin{array}{l}\text { 20-Year } \\
\text { energy } \\
\text { saving } \\
\text { (TWD) }\end{array}$ & $\begin{array}{l}\text { 20-Year total } \\
\text { investment } \\
\text { (TWD) }\end{array}$ & $\begin{array}{l}\text { PV energy } \\
\text { generation } \\
\text { cost (TWD/ } \\
\text { kWh) }\end{array}$ & $\begin{array}{l}\text { Return on } \\
\text { investment } \\
\text { (\%/year) }\end{array}$ & $\begin{array}{l}\text { PV gen- } \\
\text { eration } \\
\text { loss (\%) }\end{array}$ & $\begin{array}{l}\text { Ratio of PV } \\
\text { energy sup- } \\
\text { ply (\%) }\end{array}$ & $\begin{array}{l}\text { Lowest electric- } \\
\text { ity price category } \\
\text { for PV to be } \\
\text { economical }\end{array}$ \\
\hline \multicolumn{13}{|c|}{ Load pattern A } \\
\hline Taipei & 2.77 & 2.04 & 0.34 & 1360 & 4000 & 595,627 & 425,322 & 6.65 & 2.00 & 0.67 & 44 & 4 \\
\hline Taichung & 3.69 & 2.04 & 0.34 & 1360 & 4000 & 834,713 & 429,172 & 4.65 & 4.72 & 1.66 & 59 & 3 \\
\hline Tainan & 2.77 & 2.04 & 0.34 & 1360 & 4000 & 802,813 & 425,322 & 4.85 & 4.44 & 1.79 & 58 & 4 \\
\hline \multicolumn{13}{|c|}{ Load pattern B } \\
\hline Taipei & 3.16 & 2.38 & 0.34 & 1190 & 3500 & 517,232 & 371,538 & 6.68 & 1.96 & 1.21 & 36 & 4 \\
\hline Taichung & 3.69 & 2.04 & 0.34 & 1020 & 3000 & 629,168 & 326,004 & 4.66 & 4.65 & 0.81 & 44 & 3 \\
\hline Tainan & 3.69 & 2.04 & 0.34 & 1020 & 3000 & 606,425 & 326,004 & 4.9 & 4.30 & 0.61 & 44 & 4 \\
\hline \multicolumn{13}{|c|}{ Load pattern C } \\
\hline Taipei & 4.92 & 3.05 & 0.34 & 1020 & 3000 & 447,375 & 321,604 & 6.74 & 1.96 & 1.07 & 28 & 4 \\
\hline Taichung & 3.69 & 2.03 & 0.34 & 680 & 2000 & 416,473 & 222,836 & 4.78 & 4.34 & 0.77 & 30 & 3 \\
\hline Tainan & 3.69 & 2.03 & 0.34 & 680 & 2000 & 415,211 & 222,836 & 5.03 & 4.32 & 0.58 & 29 & 4 \\
\hline \multicolumn{13}{|c|}{ Load pattern D } \\
\hline Taipei & 5.9 & 5.09 & 0.34 & 850 & 2500 & 369,075 & 283,120 & 7.24 & 1.52 & 2.84 & 17 & 5 \\
\hline Taichung & 7.38 & 5.09 & 0.34 & 850 & 2500 & 504,338 & 286,970 & 5.09 & 3.79 & 4.07 & 20 & 4 \\
\hline Tainan & 5.90 & 5.09 & 0.34 & 850 & 2500 & 493,874 & 283,120 & 5.35 & 3.72 & 5.14 & 20 & 4 \\
\hline
\end{tabular}


Table 8 Energy storage cost comparison

\begin{tabular}{|c|c|c|c|c|}
\hline HyPV & D3 & D5 & D8 & D11 \\
\hline Battery type & LA & $\mathrm{Li}$ & LA & LA \\
\hline Nominal capacity $\left(E_{\text {bat0 }}\right)(\mathrm{kWh})$ & 4.8 & 1.44 & 2.4 & 2.4 \\
\hline Usable storage capacity $\left(E_{\text {bat }}\right)[\mathrm{kWh} @ \mathrm{DOD} 60 \%(\mathrm{LA})$ or $80 \%(\mathrm{Li})]$ & 2.88 & 1.15 & 1.44 & 1.44 \\
\hline Unit cost of battery [TWD/Wh (nominal)] & 4 & 20 & 4 & 4 \\
\hline Cost of battery @ $E_{b a t 0}(T W D)$ & 19,200 & 28,800 & 9600 & 9600 \\
\hline \multicolumn{5}{|l|}{ Water heater } \\
\hline Tank volume (L) & 120 & 120 & 120 & 120 \\
\hline Heat storage capacity $\left(E_{h}\right)(\mathrm{kWh})$ & 4.2 & 4.2 & 4.2 & 4.2 \\
\hline Cost of water heater @2 TWD/Wh (TWD) & 8400 & 8400 & 8400 & 8400 \\
\hline Total cost of dual energy storage (TWD) & 27,600 & 37,200 & 18,000 & 18,000 \\
\hline Total usable energy storage capacity $\left(E_{\text {tot }}=E_{\text {bat }}+E_{h}\right)(\mathrm{kWh})$ & 7.08 & 5.35 & 5.64 & 5.64 \\
\hline Fraction of heat storage $\left(E_{h} / E_{\text {tot }}\right)$ & 0.59 & 0.78 & 0.74 & 0.74 \\
\hline Nominal capacity of Li battery required for total energy storage $E_{\text {tot }} / 0.8(\mathrm{DOD})(\mathrm{kWh})$ & 8.85 & 6.69 & 7.05 & 7.05 \\
\hline Nominal capacity of LA battery required for total energy storage $E_{\text {tot }} / 0.6$ (DOD) (kWh) & 11.8 & 8.92 & 9.40 & 9.40 \\
\hline Total cost of energy storage $E_{\text {tot }}$ using Li battery only (TWD) & 177,000 & 133,750 & 141,000 & 141,000 \\
\hline Cost reduction by dual energy storage (TWD) & 149,400 & 96,550 & 123,000 & 123,000 \\
\hline$\%$ & 84.4 & 72.2 & 87.2 & 87.2 \\
\hline Total cost of energy storage $E_{\text {tot }}$ using LA battery only (TWD) & 47,200 & 35,680 & 37,600 & 37,600 \\
\hline Cost reduction by dual energy storage (TWD) & 19,600 & -1520 & 19,600 & 19,600 \\
\hline$\%$ & 41.5 & -4.3 & 52.1 & 52.1 \\
\hline
\end{tabular}

\section{Conclusion}

In the present study, we developed a HyPV solar home system which generates solar power for self-consumption and utilizes dual energy storage. The solar home system utilizes a switching-type solar PV system (HyPV) which operates in either solar or grid mode automatically. No solar power is fed into grid. The combined battery and thermal storage can reduce the system cost since thermal storage is much cheaper than battery. An electric water heater is used to store solar PV energy when the battery is full. Four HyPV solar home systems were built for long-term field test. The test results show that the specific PV energy generation approximates that of FIT PV system.

An economic analysis was also carried out. The cost of dual energy storage as well as the system cost is reduced since thermal storage is much cheaper. It shows that the PV energy generation cost is lower than the electricity price from grid if the system is properly designed. That is, HyPV solar home system with dual storage is economic if it was used to substitute partial energy demand which is paid at higher grid electricity price. This verifies the possibility of grid parity for a solar PV system with energy storage.
Acknowledgements This study was supported by National Energy Program II, MOST 103-3113-E-002-006 and MOST 103-2221-E-002231-MY2, made by Ministry of Science and Technology, Taiwan. Technical and financial support from E-SUN Precision Incdustrial Co. (Taiwan) is also appreciated.

\section{Compliance with ethical standards}

Conflict of interest On behalf of all authors, the corresponding author states that there is no conflict of interest.

\section{References}

1. Hsu PC, Huang BJ, Lin WC, Chang YJ, Chang CJ, Li K, Lee KY (2016) Effect of switching scheme on the performance of a hybrid solar PV system. Renew Energy 96:520-530

2. Hsu P-C, Huang B-J, Wu P-H, Wu W-H, Lee M-J, Yeh J-F, Wang Y-H, Tsai J-H, Li K, Lee K-Y (2017) Long-term energy generation efficiency of solar PV system for self-consumption. Energy Procedia 141:91-95

3. Huang B-J, Hsu P-C, Wu P-H, Wang Y-H, Tang T-C, Wang J-W, Dong $\mathrm{X}-\mathrm{H}, \mathrm{Wu} \mathrm{W}-\mathrm{H}$, Lee M-J, Yeh J-F (2017) Hybrid energy storage of solar PV system for self-consumption. In: International conference \& workshop REMOO-2017. Energy for tomorrow, 10-12 May 2017, Venice, Italy 
4. Bocklisch T (2015) Hybrid energy storage systems for renewable energy applications. Energy Procedia 73:103-111. https ://doi.org/10.1016/j.egypro.2015.07.582

5. Lee SC (2011) Operation analysis of a photovoltaic lighting system with battery and heater. Sol Energy 85:2144-2153. https://doi.org/10.1016/j.solener.2011.06.002

6. Akbari $\mathrm{H}$, Browne MC, Ortega A, Huang MJ, Hewitt NJ, Norton B, McCormack SJ (2019) Efficient energy storage technologies for photovoltaic systems. Sol Energy. https://doi. org/10.1016/j.solener.2018.03.052

7. Faccia AL, Krastev VK, Falcucci G, Ubertinia S (2019) Smart integration of photovoltaic production, heat pump and thermal energy storage in residential applications. Sol Energy. https:// doi.org/10.1016/j.solener.2018.06.017
8. Thim F, Rothert M, Kever F (2014) Where is the optimum? Comparison of system topologies for small PV hybrid systems. In: 7th international PV-hybrid and mini-grid conference, 10-11 April 2014. Bad Hersfeld, Germany

9. Nguyen HT, Nguyen DT, Le LB (2014) Energy management for households with solar assisted thermal load considering renewable energy and price uncertainty. IEEE Trans Smart Grid 6(1):301-314

Publisher's Note Springer Nature remains neutral with regard to jurisdictional claims in published maps and institutional affiliations. 